\title{
Multi Element Microstrip Antenna Arrays Using Electromagnetic Band Gap Structures
}

\author{
${ }^{* 1}$ K. Prahlada Rao, ${ }^{2}$ Vani R.M, ${ }^{3}$ P.V. Huanagund \\ ${ }^{1,3}$ Dept. of PG Studies and Research in Applied Electronics, Gulbarga University, Gulbarga, India. \\ ${ }^{2}$ University Science Instrumentation Centre, Gulbarga University, Gulbarga, India. \\ Email:pra_kaluri@rediffmail.com
}

Received: $28^{\text {th }}$ May 2018, Accepted: $10^{\text {th }}$ July 2018, Published: $31^{\text {st }}$ August 2018

\begin{abstract}
This paper discusses the improvement in the performance of two, four and eight element microstrip antenna array using Electromagnetic Band Gap structures. The antenna arrays are designed at $6 \mathrm{GHz}$. The dielectric substrate used is FR-4 glass epoxy with dielectric constant of 4.2 and loss tangent of 0.0245 . The two element conventional antenna array is producing bandwidth of $2.35 \%$ and gain of 5.06 $\mathrm{dB}$. The modified two element antenna array is producing greater bandwidth of $61.12 \%$ and higher gain $8.34 \mathrm{~dB}$. The four element conventional antenna array is producing bandwidth of $4.89 \%$ and gain of $6.81 \mathrm{~dB}$. The modified four element antenna array is producing improved bandwidth of $73.39 \%$ and gain of $11.09 \mathrm{~dB}$. The eight element conventional antenna array is producing bandwidth of $4.98 \%$ and gain of $7.44 \mathrm{~dB}$. The modified eight element antenna array is producing enhanced bandwidth of $85.74 \%$ and healthier gain of $13.77 \mathrm{~dB}$. All the modified microstrip antenna arrays show appreciable decrease in mutual coupling compared to their respective conventional antenna arrays. The radiation characteristics of the modified antenna arrays depict good reduction in back lobe radiation. The antenna arrays are designed using IE3D simulation software and measured results are obtained using vector network analyzer.
\end{abstract}

Keywords: Microstrip Antenna Array; Return Loss; Back Lobe Radiation; Frequency.

\section{Introduction}

The field of microwave antenna engineering has found innumerable applications in diversified areas of research in our everyday life. High data transfer rates accompanied with quality transmission and reception of information is the foremost criteria to be satisfied in communication systems. The boom in antenna engineering has opened a window for the discovery of new antennas called as microstrip antennas. Surface waves emanating from the dielectric substrate of microstrip antennas and arrays, lead to serious repercussions on antenna radiation properties and their characteristics. These antennas are employed in resonators, waveguides, high end communication systems and radars. The structure of a microstrip antenna consists of a dielectric substrate present between the radiating patch and finite ground plane. Microstrip antennas have pioneered many engineers because of their advantages like light weight, ease of fabrication, conformal and planar type of structure etc. [1-7].

In recent years, Electromagnetic Band Gap (EBG) structures have earned their place in antenna and microwave engineering because of their important feature of reduction of effect of surface waves on microstrip antennas and arrays. The EBG structures are periodic in nature and are used to reduce the mutual coupling between the antenna array elements. These structures also help microstrip antennas and arrays in attaining high bandwidths as these are classified as narrow band width antennas. Researchers have come up with various types of EBG design structures to enhance the performance of these antennas. [8-17].

\section{Design of Conventional Antenna Array}

The two element conventional microstrip antenna array (TECMAA) consists of two identical rectangular elements fed by corporate feeding technique. Fig.1 depicts the schematic of TECMAA.

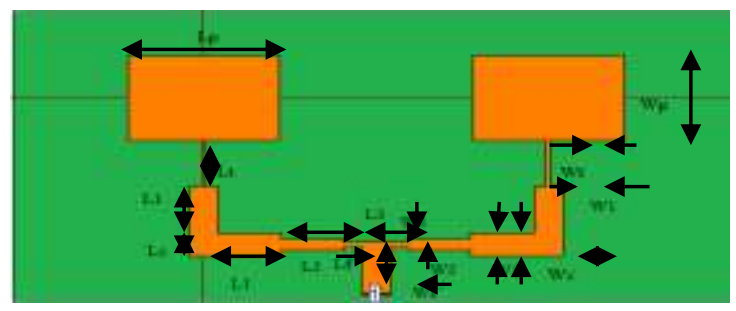

Fig.1. Schematic of TECMAA.

The distance between the two antenna elements is equal to $\lambda / 4$, where $\lambda$ is the wavelength calculated at the design frequency of $6 \mathrm{GHz}$. At the design frequency of $6 \mathrm{GHz}$, the dimensions of each of the radiating patches are $15.73 \mathrm{~mm}$ $\times 11.76 \mathrm{~mm}$. The dimensions of other parts of TECMAA are tabulated in Table I.

To determine the mutual coupling between the adjacent antenna elements, the two radiating patches of TECMAA are excited separately as shown in Fig. 2.

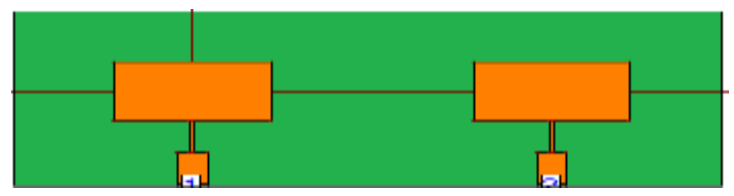

Fig.2. Schematic of setup of TECMAA for the measurement of mutual coupling. 


\begin{tabular}{|c|c|}
\hline Parameter & Value(mm) \\
\hline Length of the patch (Lp) & 15.73 \\
\hline Width of the patch (Wp) & 11.76 \\
\hline Length of the quarter wave transformer (Lt) & 6.47 \\
\hline Width of the quarter wave transformer (Wt) & 0.47 \\
\hline Length of the $50 \Omega$ line (L1) & 6.52 \\
\hline Width of the $50 \Omega$ line (W1) & 3.05 \\
\hline Length of the coupler (Lc) & 3.05 \\
\hline Width of the coupler (Wc) & 3.05 \\
\hline Length of the $70 \Omega$ line (L3) & 6.54 \\
\hline Width of the $70 \Omega$ line (W3) & 1.62 \\
\hline Length of the $100 \Omega$ line (L2) & 6.56 \\
\hline Width of the $100 \Omega$ line (W2) & 0.70 \\
\hline Length of the feed line (Lf) & 6.52 \\
\hline Width of the feed line (Wf) & 3.05 \\
\hline
\end{tabular}

\section{TABLE I. Dimensions of TECMAA}

In Fig. 2 the distance between the two antenna elements is maintained constant as that in Fig.1. It is assumed that both the radiating patches are fed with equal amount of power.

The four element conventional microstrip antenna array (FECMAA) consists of four identical radiating patches which are rectangular in shape. The schematic of FECMAA is shown in Fig. 3. All the dimensions of TECMAA mentioned in Table I are applicable for FECMAA. The distance between the two adjacent elements of FECMAA is maintained constant as that in TECMAA. The schematic of FECMAA is depicted in Fig.3.

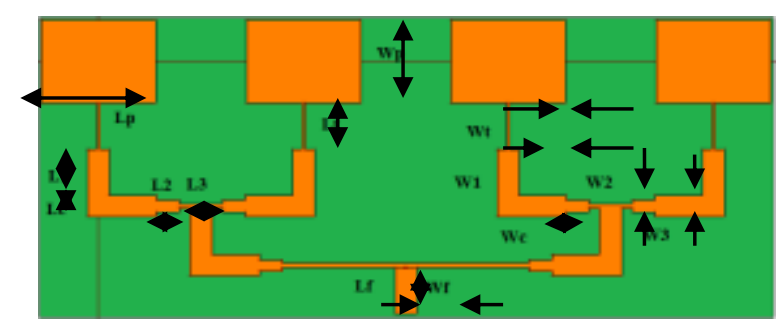

Fig.3. Schematic of FECMAA.

To determine the mutual coupling between the adjacent antenna elements, the four radiating patches of FECMAA are excited separately as shown in Fig.4.

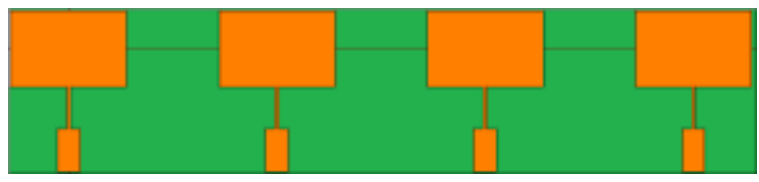

Fig.4. Schematic of Setup of FECMAA for the Measurement of Mutual Coupling.

In Fig. 4 the distance between the two adjacent antenna elements is maintained constant as that in Fig.3. It is

assumed that the four radiating patches are fed with equal amount of power.

The eight element conventional microstrip antenna array (EECMAA) consists of eight identical radiating patches which are rectangular in shape. The schematic of EECMAA is shown in Fig. 5. All the dimensions of TECMAA mentioned in Table I are applicable for EECMAA. The distance between the two adjacent elements of EECMAA is maintained constant as that in TECMAA and FECMAA.

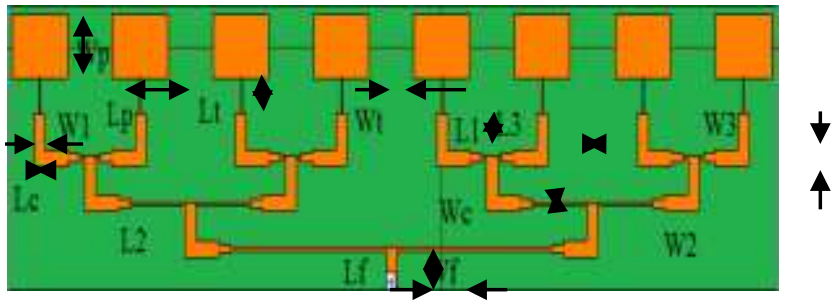

Fig.5. Schematic of EECMAA.

To determine the mutual coupling between the adjacent antenna elements, the eight radiating patches of EECMAA are excited separately as shown in Fig.6.

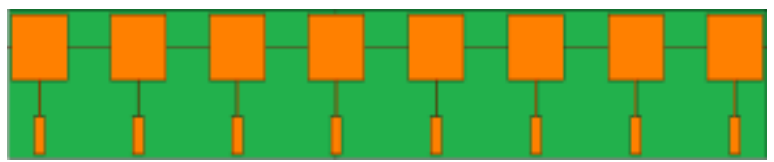

Fig.6. Schematic of setup of EECMAA for the measurement of mutual coupling.

In Fig. 6 the distance between the two adjacent antenna elements is maintained constant as that in Fig.5. It is assumed that the eight radiating patches are fed with equal amount of power.

\section{Design of Proposed Antenna Array}

The proposed microstrip antenna arrays designed are two element proposed microstrip antenna array (TEPMAA), four element proposed microstrip antenna array (FEPMAA) and eight element proposed microstrip antenna array (EEPMAA).

TEPMAA is designed by modifying the ground plane and the surface of TECMAA with EBG structures. The unit cells employed to design the EBG structures in the ground plane and on the surface are shown in Figs. 7 and 8 respectively. In Figs.7 and $8, \mathrm{P}=9 \mathrm{~mm}, \mathrm{Q}=3.3 \mathrm{~mm}, \mathrm{~B}=$ $4 \mathrm{~mm}$ and $\mathrm{C}=1.5 \mathrm{~mm}$.

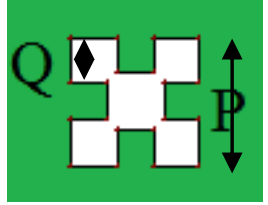

Fig.7. Schematic of Unit Cell of EBG Structure Employed in the Ground Plane. 


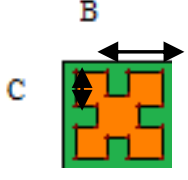

Fig.8. Schematic of Unit Cell of EBG Structure Employed on the Surface.

The EBG structures employed to design TEPMAA are shown in Fig.9 and 10 respectively.

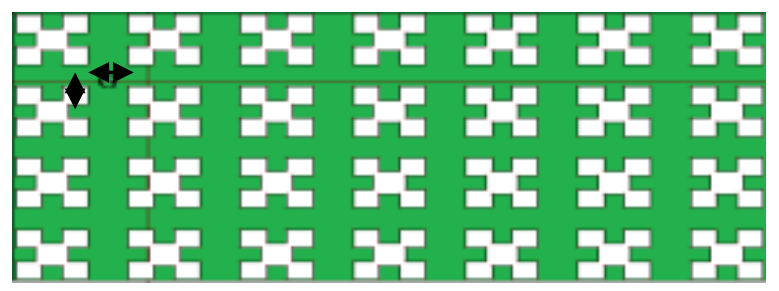

Fig. 9. Schematic of Fractal Slot Type EBG

Structure Used in the Ground Plane of TEPMAA.

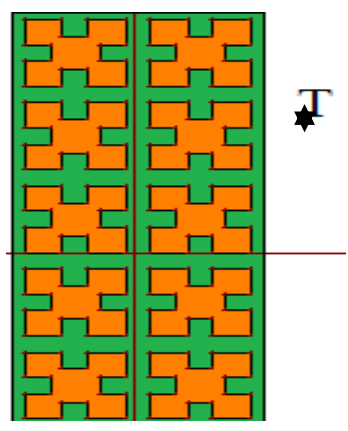

Fig. 10. Schematic of Fractal Patch Type EBG Structure Used on the Surface of TEPMAA.

The ground plane of TEPMAA consists of a matrix of 7 columns and 4 rows of fractal slot type EBG structure and the surface of TEPMAA is loaded with a matrix of 2 columns and 5 rows of fractal patch type EBG structure. The fractal patch type EBG structure is placed in between the two radiating elements. The unit cells of the EBG structure employed in the ground plane are repeated after every $\mathrm{G}=5 \mathrm{~mm}$. On the surface of TEPMAA, the unit cells of the EBG structure are periodically placed at a distance of $T=1 \mathrm{~mm}$. The schematic of TEPMAA is depicted in Fig. 11 and the schematic of setup of TEPMAA used to determine the mutual coupling is shown in Fig. 12.

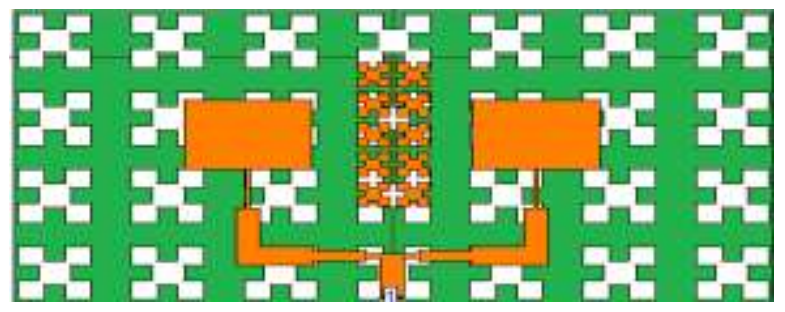

Fig.11. Schematic of TEPMAA.

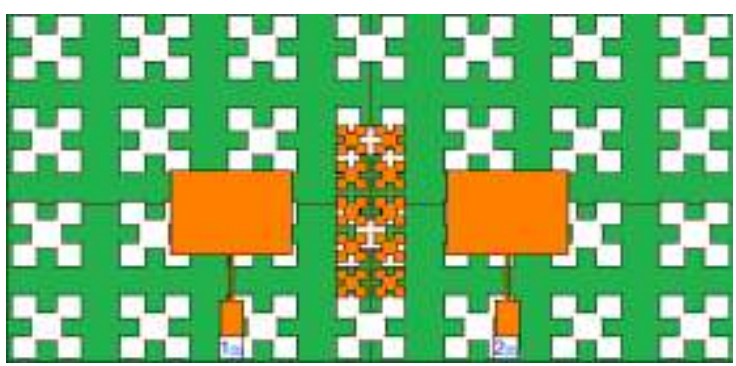

Fig. 12. Schematic of Setup of TEPMAA for the Measurement of Mutual Coupling.

FEPMAA is designed by modifying the ground plane and the surface of FECMAA with EBG structures. The unit cells employed to design FEPMAA are same as that depicted in Figs. 7 and 8. FEPMAA is designed by loading the ground plane with a matrix of 9 columns and 4 rows of fractal slot type EBG structure and the surface with a matrix of 2 columns and 5 rows of fractal patch type EBG structure. The EBG structures employed to design FEPMAA are depicted in Figs. 13 and 14 respectively.

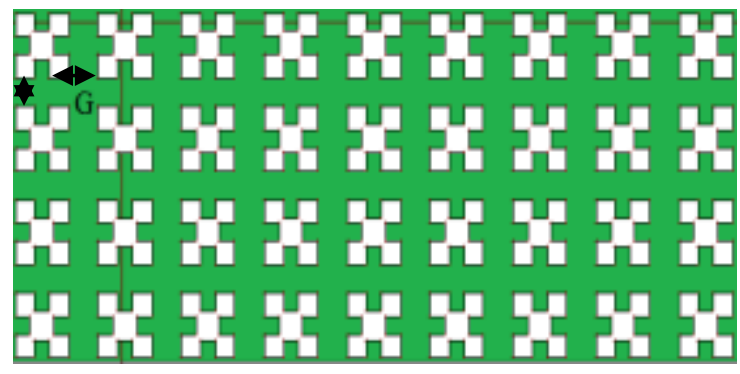

Fig. 13. Schematic of Fractal Slot Type EBG Structure Used in the Ground Plane of FEPMAA.

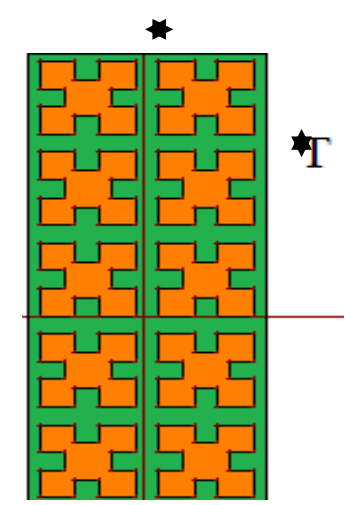

Fig. 14. Schematic of Fractal Patch Type EBG Structure Used on the Surface of FEPMAA.

The fractal patch type EBG structure is placed in between the adjacent radiating elements. The periodicity of the unit cells of the EBG structure employed in the ground plane is $\mathrm{G}=5 \mathrm{~mm}$. The distance between the adjacent unit cells of the EBG placed on the surface of FEPMAA is $\mathrm{T}=1 \mathrm{~mm}$. Fig.15 shows the schematic of FEPMAA and Fig.16 depicts the setup of FEPMAA employed to determine the mutual coupling between the adjacent antenna elements. 


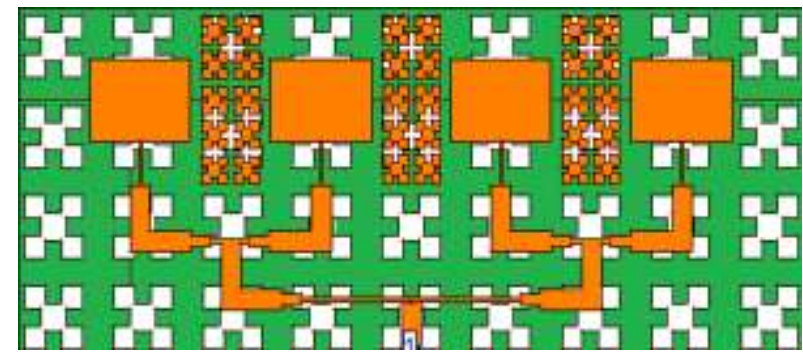

Fig.15. Schematic of FEPMAA.

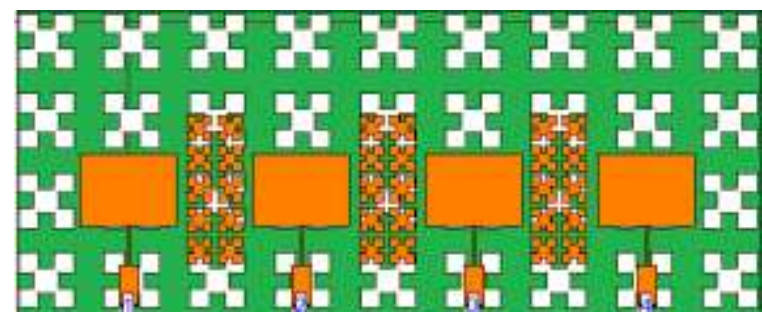

Fig. 16. Schematic of Setup of FEPMAA for the Measurement of Mutual Coupling.

EEPMAA is designed by modifying the ground plane and the surface of EECMAA with EBG structures. The unit cells employed to design EEPMAA are same as that depicted in Figs. 7 and 8. The ground plane of EEPMAA consists of a matrix of 15 columns and 5 rows of fractal slot type EBG structure and the surface of EEPMAA is made of a matrix of 2 columns and 5 rows of fractal patch type EBG structure. The EBG structures used as part of EEPMAA are depicted in Figs. 17 and 18 respectively.

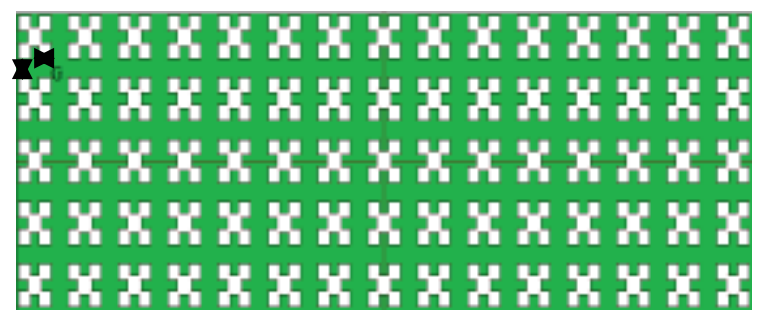

Fig. 17. Schematic of Fractal Slot Type EBG Structure Used in the Ground Plane of EEPMAA.

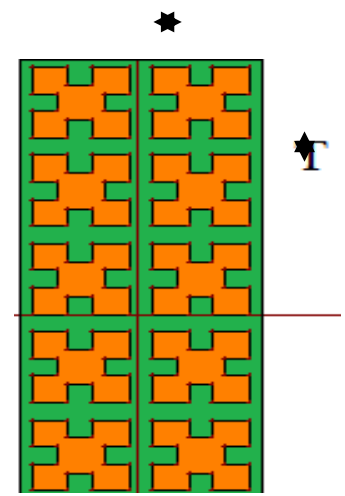

Fig. 18. Schematic of Fractal Patch Type EBG Structure Used on the Surface of EEPMAA.
The fractal patch type EBG structure is placed in between the adjacent antenna elements. The unit cells of the EBG structure employed in the ground plane are repeated along $\mathrm{x}$-axis and $\mathrm{y}$-axis after every $\mathrm{G}=5 \mathrm{~mm}$. The periodicity of the unit cells of the EBG structure placed on the surface of EEPMAA is $\mathrm{T}=1 \mathrm{~mm}$. Fig. 19 shows the schematic of EEPMAA and Fig.20 depicts the setup of EEPMAA employed to determine the mutual coupling between the adjacent antenna elements.

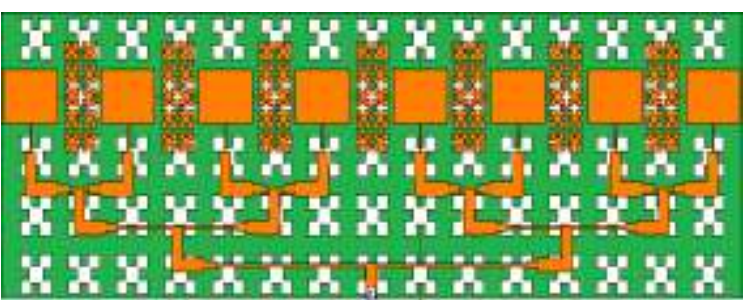

Fig.19. Schematic of EEPMAA.

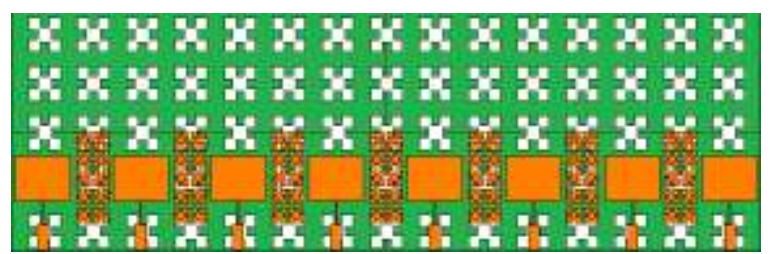

Fig. 20. Schematic of Setup of EEPMAA for the Measurement of Mutual Coupling.

Photographs of Fabricated Antenna Arrays

The photographs of the fabricated antenna arrays are shown in Figs. 21, 22, 23, 24, 25, 26, 27, 28, 29, 30, 31 and 32 respectively.

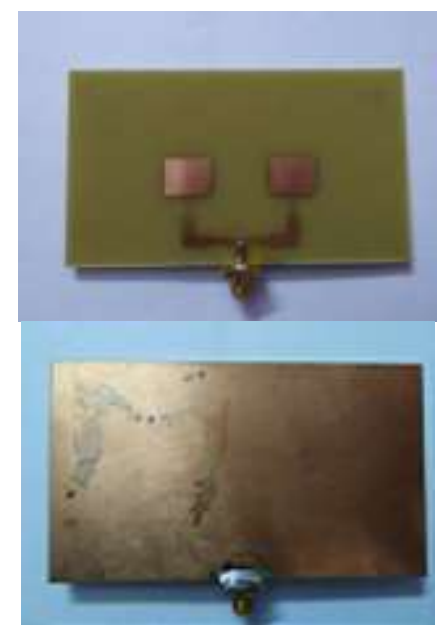

Fig.21. Photograph of TECMAA. (a) Front View

(b) Back View. 


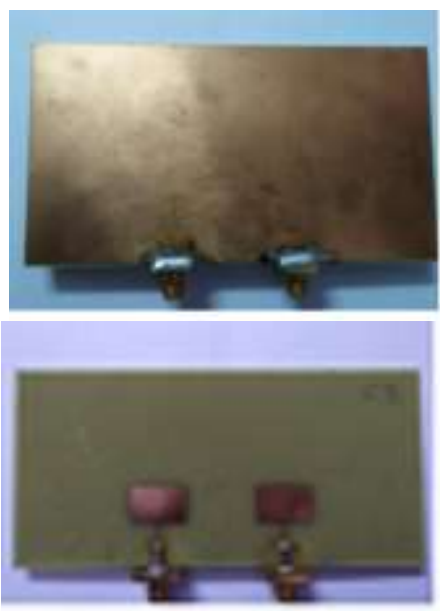

Fig.22.Photograph of TECMAA Arrangement for Mutual Coupling Measurement.

(a) Front View

(b) Back View

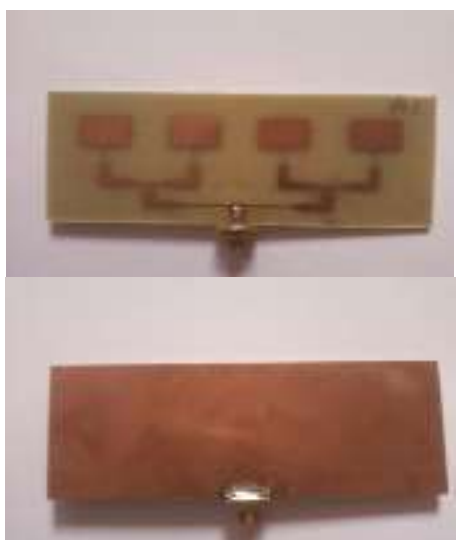

Fig. 23. Photograph of FECMAA.

(a) Front View

(b) Back View

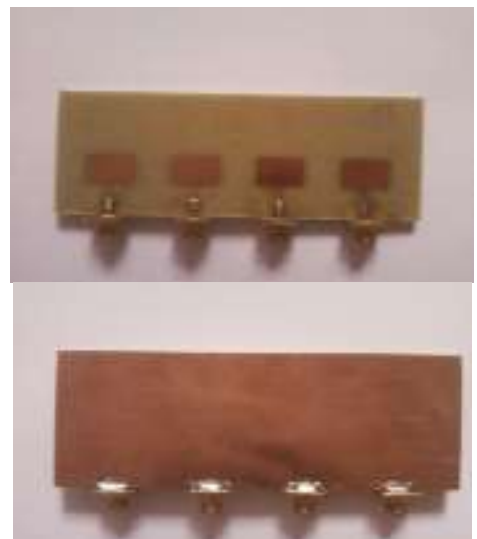

Fig. 24. Photograph of FECMAA Arrangement for Mutual Coupling Measurement.

(a) Front View

(b) Back View

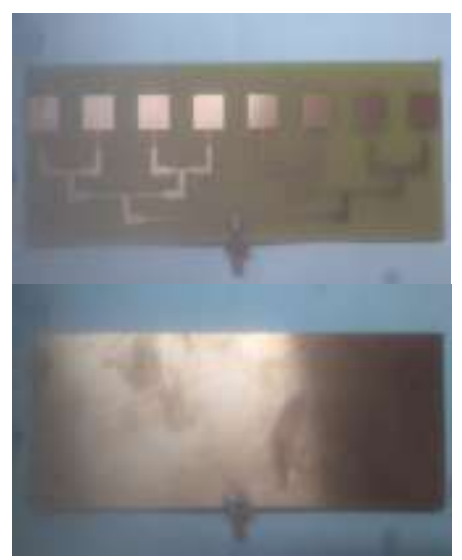

Fig. 25. Photograph of EECMAA.
(a) Front view
(b) Back view

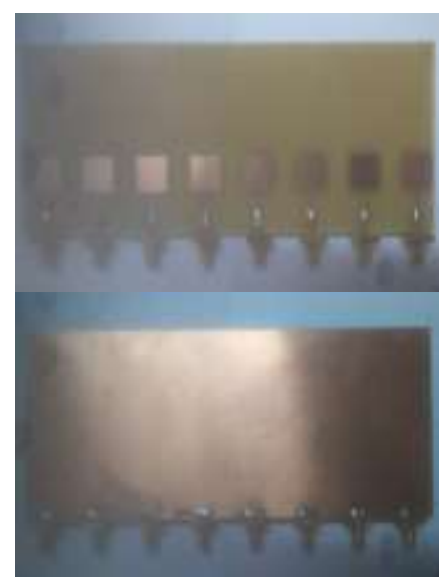

Fig. 26. Photograph of EECMAA Arrangement for Mutual Coupling Measurement.

(a) Front view

(b) Back view

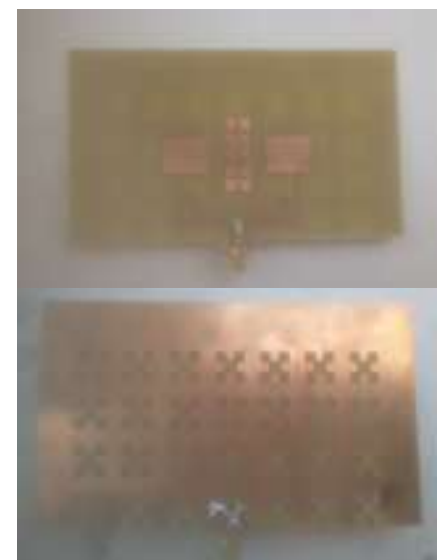

Fig.27. Photograph of TEPMAA.

(a) Front View

(b) Back View 


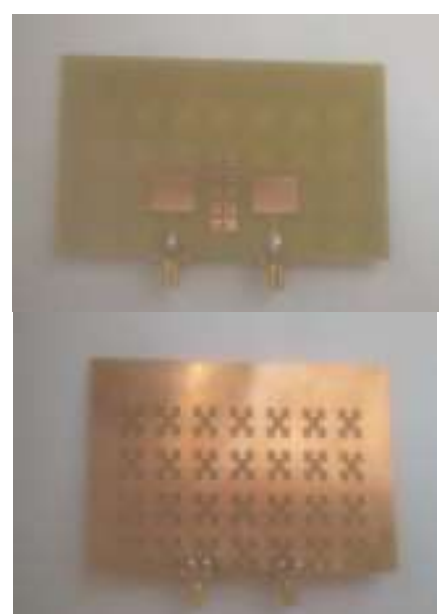

Fig.28. Photograph of TEPMAA Arrangement for Mutual Coupling Measurement.

(a) Front View

(b) Back View.

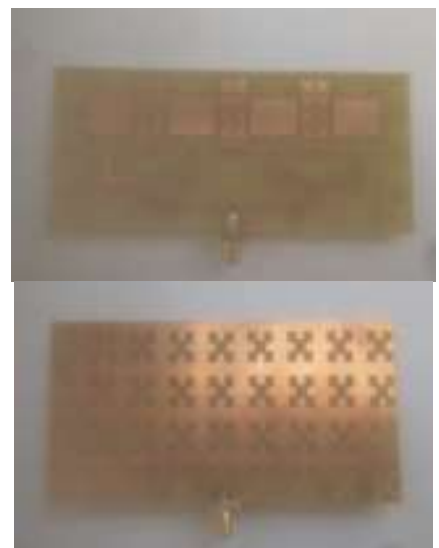

Fig. 29. Photograph of FEPMAA.

(a) Front View

(b) Back View

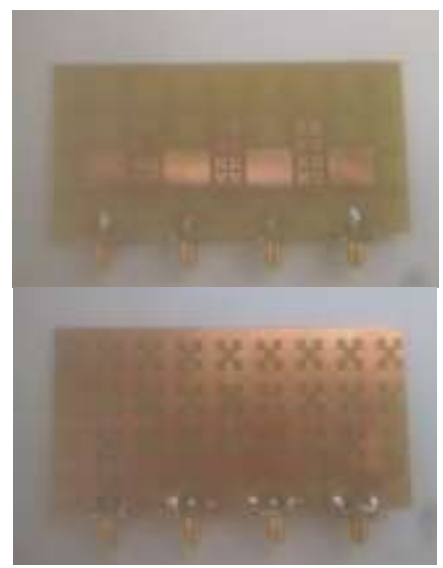

Fig.30. Photograph of FEPMAA Arrangement for Mutual Coupling Measurement.

(a) Front View

(b) Back View.

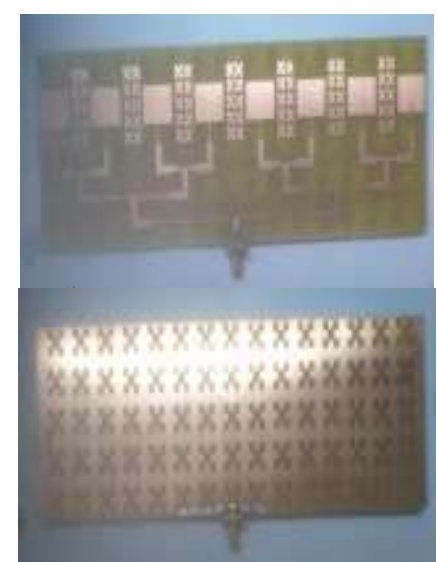

Fig. 31. Photograph of EEPMAA.
(a) Front View
(b) Back View

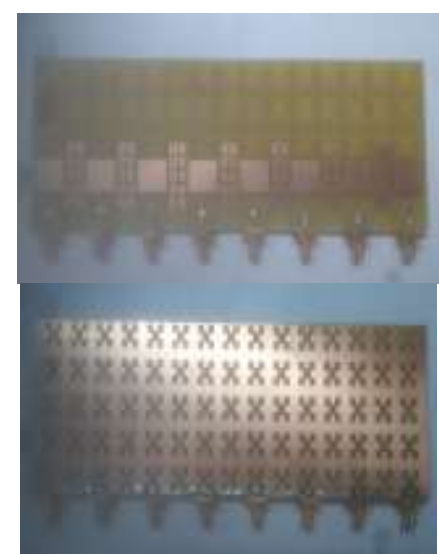

Fig.32. Photograph of EEPMAA Arrangement for Mutual Coupling Measurement.
(a) Front View
(b) Back View.

\begin{abstract}
Measured Results
The measured results of the microstrip antenna arrays TECMAA, FECMAA, EECMAA, TEPMAA, FEPMAA and EEPMAA are obtained using vector network analyzer. The conventional and proposed antenna arrays are compared in terms of return loss, resonant frequency, bandwidth (\%), mutual coupling, gain, forward power, back lobe radiation, front to back ratio (FBR) and virtual size reduction $(\%)$. The frequency range over which the measured results are taken is 1-7 GHz. The return loss and mutual coupling versus frequency graph of TECMAA is shown in Fig.33.
\end{abstract}




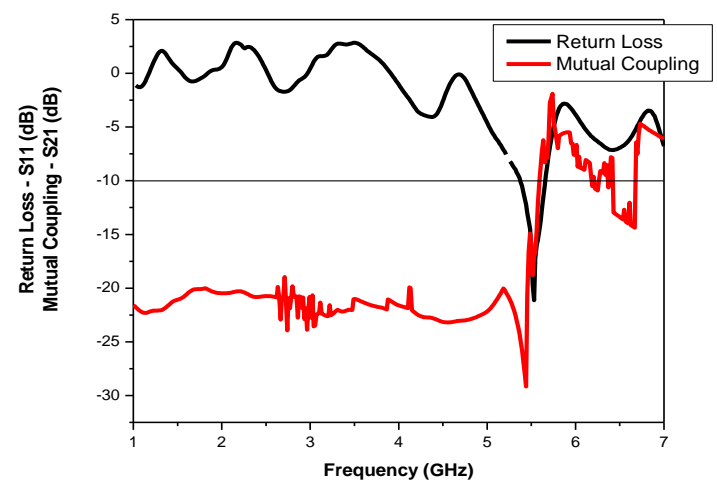

Fig.33. Plot of Return Loss and Mutual Coupling versus Frequency of TECMAA.

The return loss and mutual coupling measured for TECMAA are designated by $S_{11}$ and $S_{21}$ respectively. The design frequency of TECMAA being $6 \mathrm{GHz}$ is resonating at $5.53 \mathrm{GHz}$ and producing a return loss equal to -21.23 $\mathrm{dB}$. At the resonant frequency of $5.53 \mathrm{GHz}$, the measured value of mutual coupling is $-17.83 \mathrm{~dB}$. We see from Fig.33, the return loss and mutual coupling plots are crossing each other at the resonant frequency of $5.53 \mathrm{GHz}$. This implies that TECMAA is suffering from interference problem between the two antenna elements. This leads to huge amount of data loss and improper transmission and reception between the transmitting antenna and the receiving antennas. Moreover, the mutual coupling of $17.83 \mathrm{~dB}$ is considered to be high value as it is greater than $-20 \mathrm{~dB}$ and needs to be decreased.

From Fig.33, the parameter bandwidth can also be evaluated. Bandwidth is obtained by subtracting the lower frequency from the upper frequency where the return loss is crossing the $-10 \mathrm{~dB}$ value on either side of the resonant frequency. The calculated bandwidth of TECMAA is 130 MHz. The bandwidth (\%) is determined by using the formula

$$
\frac{\text { Bandwith }}{\text { Resonant frequency }} \times 100 \%
$$

TECMAA is producing bandwidth (\%) of $2.35 \%$. This bandwidth $(\%)$ is considered to be very narrow and needs to be increased.

The graphs of return loss and mutual coupling versus frequency of FECMAA are depicted in Figs.34, 35 and 36 respectively.

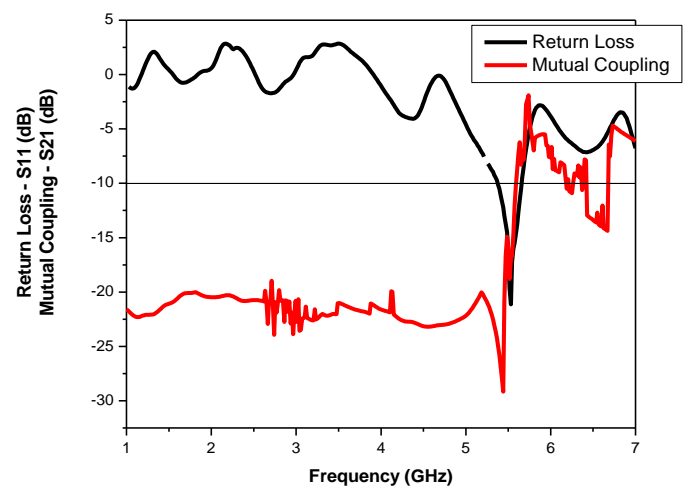

Fig.34. Plot of Return Loss and Mutual Coupling $S_{21}$ versus Frequency of FECMAA.

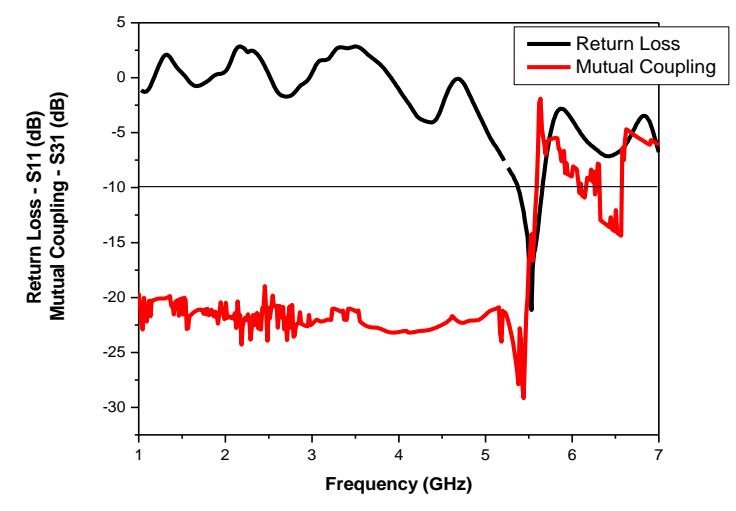

Fig.35. Plot of Return Loss and Mutual Coupling $\mathrm{S}_{31}$ versus Frequency of FECMAA.

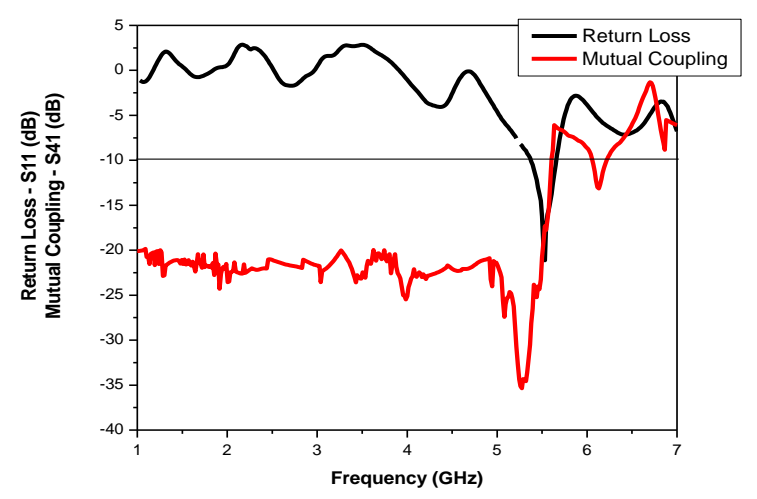

Fig.36. Plot of Return Loss and Mutual Coupling $\mathrm{S}_{41}$ versus Frequency of FECMAA.

The return loss and mutual coupling measured for FECMAA are $S_{11}, S_{21}, S_{31}$ and $S_{41}$ respectively. From Figs. 34,35 and 36 we see that FECMAA is resonating at 5.53 $\mathrm{GHz}$ with a return loss of $-21.06 \mathrm{~dB}$. FECMAA is producing a bandwidth of $273 \mathrm{MHz}$. Hence the bandwidth 
(\%) is equal to $4.89 \%$. The bandwidth (\%) of FECMAA is very narrow and needs to be enhanced.

As far as the parameter mutual coupling is concerned, the values of these parameters at the resonant frequency of $5.53 \mathrm{GHz}$ are $\mathrm{S}_{21}=-16.95 \mathrm{~dB}, \mathrm{~S}_{31}=-14.22 \mathrm{~dB}$ and $\mathrm{S}_{41}=-$ $17.30 \mathrm{~dB}$ respectively. The values of mutual coupling coefficients are very high as they are greater than $-20 \mathrm{~dB}$. Additionally, Figs. 34, 35 and 36 depict that the return loss and mutual coupling plots are overlapping, thus indicating high level of interference between the transmitting antenna 1 and the receiving antennas 2, 3 and 4 respectively. This leads to huge amount of data loss and improper transmission and reception between the transmitting antenna and the receiving antennas.

The graphs of return loss and mutual coupling versus frequency of EECMAA are depicted in Figs.37, 38, 39, 40, 41,42 and 43 respectively.

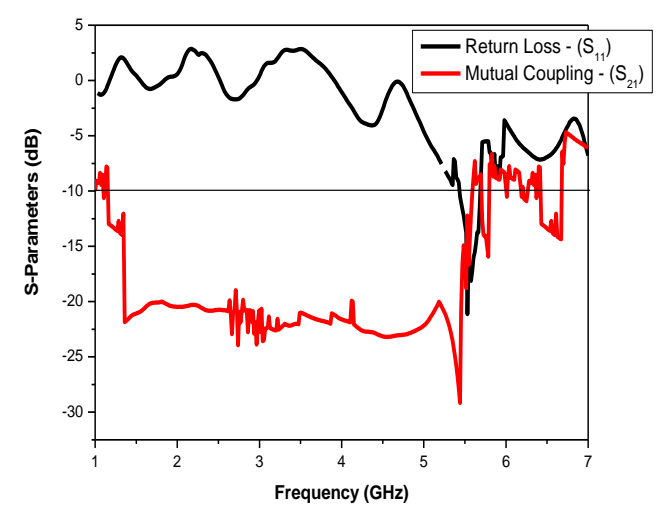

Fig.37. Plot of Return Loss and Mutual Coupling $S_{21}$ versus Frequency of EECMAA.

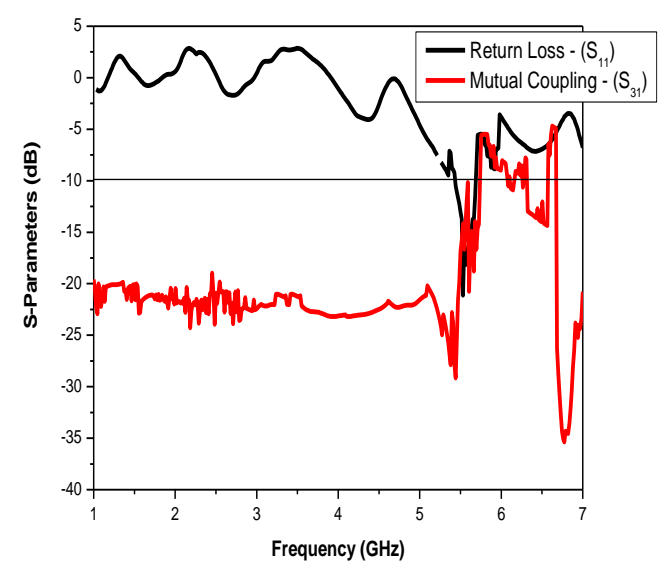

Fig.38. Plot of Return Loss and Mutual Coupling $S_{31}$ versus Frequency of EECMAA.

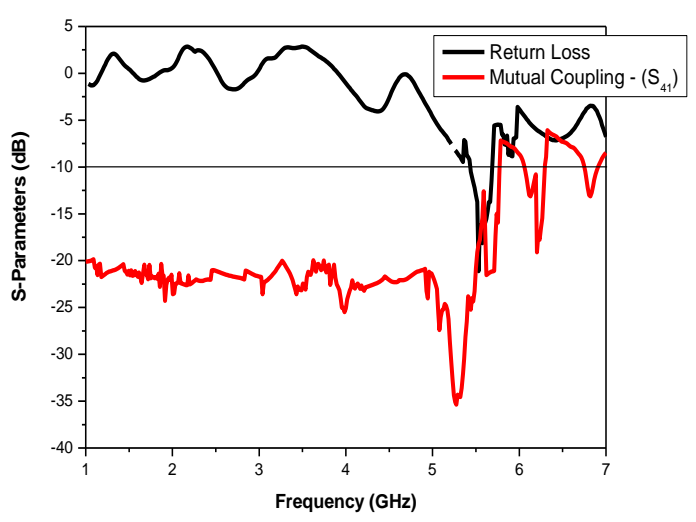

Fig.39. Plot of Return Loss and Mutual Coupling $S_{41}$ versus Frequency of EECMAA.

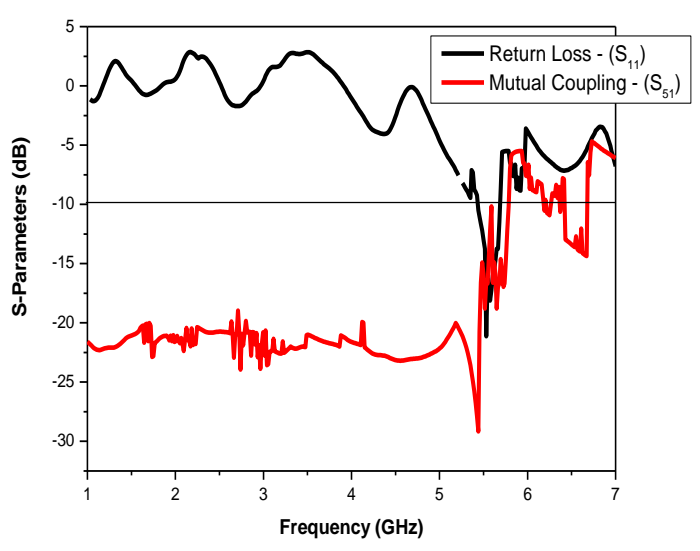

Fig.40. Plot of Return Loss and Mutual Coupling $S_{51}$ versus Frequency of EECMAA

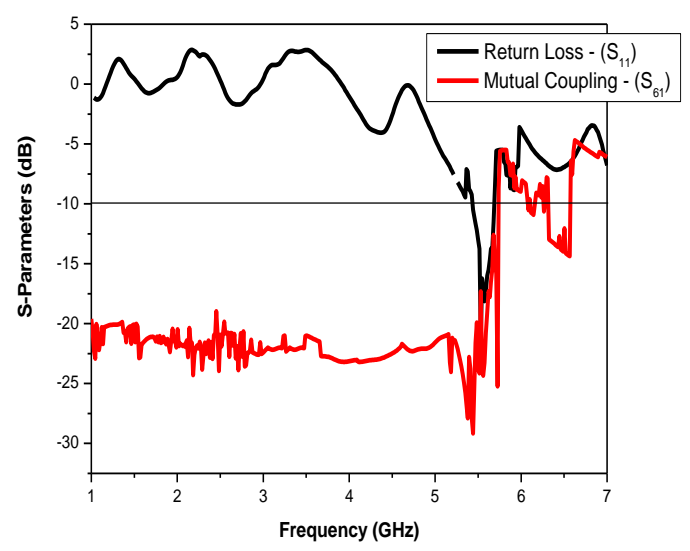

Fig.41. Plot of Return Loss and Mutual Coupling S61 $_{61}$ versus Frequency of EECMAA 


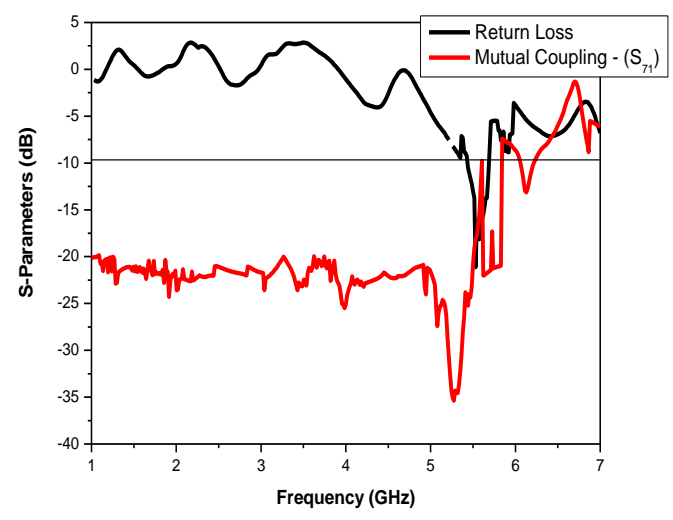

Fig.42. Plot of Return Loss and Mutual Coupling $S_{71}$ versus Frequency of EECMAA

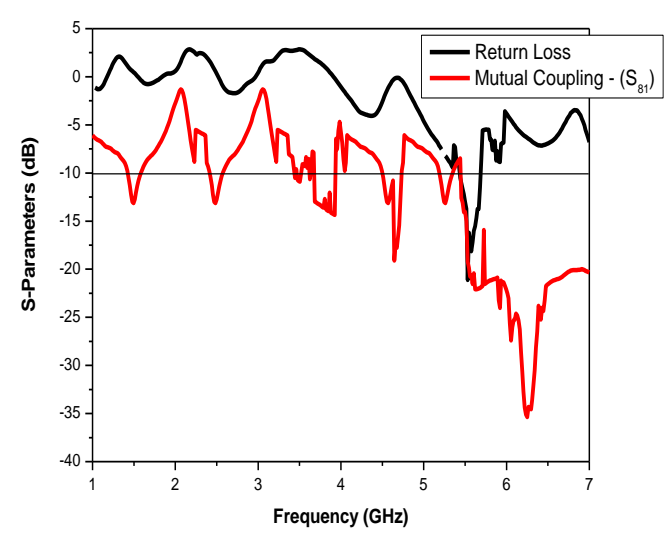

Fig.43. Plot of Return Loss and Mutual Coupling $S_{81}$ versus Frequency of EECMAA

The return loss and mutual coupling measured for FECMAA are $\mathrm{S}_{11}, \mathrm{~S}_{21}, \mathrm{~S}_{31}, \mathrm{~S}_{41}, \mathrm{~S}_{51}, \mathrm{~S}_{61}, \mathrm{~S}_{71}$ and $\mathrm{S}_{81}$ respectively. Figs. 37, 38, 39, 40, 41, 42 and 43 depict that EECMAA is resonating at $5.53 \mathrm{GHz}$. The return loss measured at the resonant frequency of $5.53 \mathrm{GHz}$ is -21.12 $\mathrm{dB}$. The calculated bandwidth of EECMAA is equal to 275 $\mathrm{MHz}$. Thus the calculated bandwidth (\%) is equal to 4.97 $\%$. The bandwidth (\%) of EECMAA is very narrow.

From Figs. 37, 38, 39, 40, 41, 42 and 43, at the resonant frequency of $5.53 \mathrm{GHz}$, EECMAA is producing serious and detrimental values $(>-20 \mathrm{~dB})$ of mutual coupling equal to $\mathrm{S}_{21}=-12.22 \mathrm{~dB}, \mathrm{~S}_{31}=-14.18 \mathrm{~dB}, \mathrm{~S}_{41}=-18.23 \mathrm{~dB}, \mathrm{~S}_{51}=$ $-16.45 \mathrm{~dB}, \mathrm{~S}_{61}=-17.31 \mathrm{~dB}, \mathrm{~S}_{71}=-18.09 \mathrm{~dB}$ and $\mathrm{S}_{81}=-$ $19.23 \mathrm{~dB}$ respectively. Moreover, from Figs. 37, 38, 39, 40, 41, 42 and 43 it is clearly visible that the plots of return loss and mutual coupling are overlapping each other at the resonant frequency of $5.53 \mathrm{GHz}$. This overlapping leads to improper transfer of information between the transmitting antenna 1 and the receiving antennas 2, 3, 4, 5, 6, 7 and 8 respectively with low data transfer rate.
Fig.44 shows the graph of return loss and mutual coupling of TEPMAA.

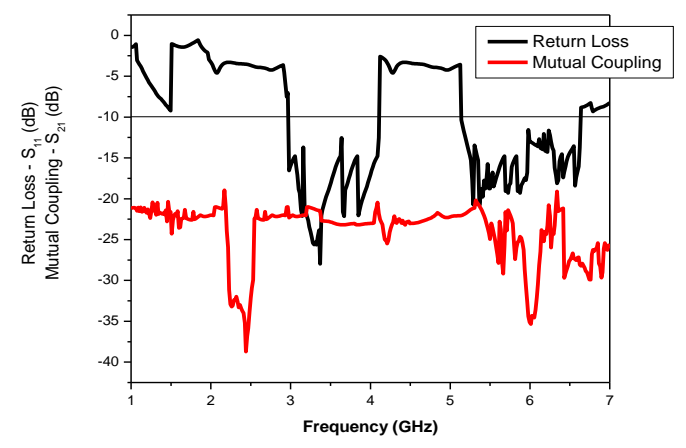

Fig.44. Plot of Return Loss and Mutual Coupling $\mathrm{S}_{21}$ versus Frequency of TEPMAA.

From Fig.44, TEPMAA is resonating at 3.36 and 5.53 GHz. The individual bandwidths measured at the corresponding resonant frequencies are 1150 and 1510 Mhz respectively. Therefore, the overall bandwidth of TEPMAA is equal to $61.52 \%$. Hence the overall bandwidth (\%) of TEPMAA is enhanced to $61.12 \%$ as compared to $2.35 \%$ of TECMAA. The value of mutual coupling measured at the resonant frequency of $5.53 \mathrm{GHz}$ for TEPMAA is $-24.76 \mathrm{~dB}$. We see that the mutual coupling of TECMAA is reduced from $-17.83 \mathrm{~dB}$ to -24.76 $\mathrm{dB}$ with the introduction of $\mathrm{EBG}$ structures. Other noticeable feature of TEPMAA is that the plots of return loss and mutual coupling are not crossing each other at the resonant frequency of $5.53 \mathrm{GHz}$. This leads to reduction of interference between the transmitting antenna 1 and the receiving antenna 2 . Hence TEPMAA is showing improved performance than TECMAA in terms of bandwidth (\%) and mutual coupling.

Figs.45, 46 and 47 show the graphs of return loss and mutual coupling of FEPMAA.

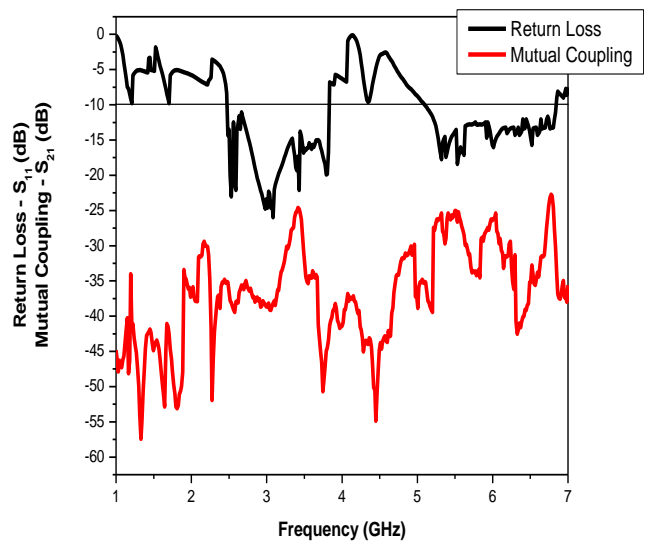

Fig.45. Plot of Return Loss and Mutual Coupling $S_{21}$ versus Frequency of FEPMAA. 


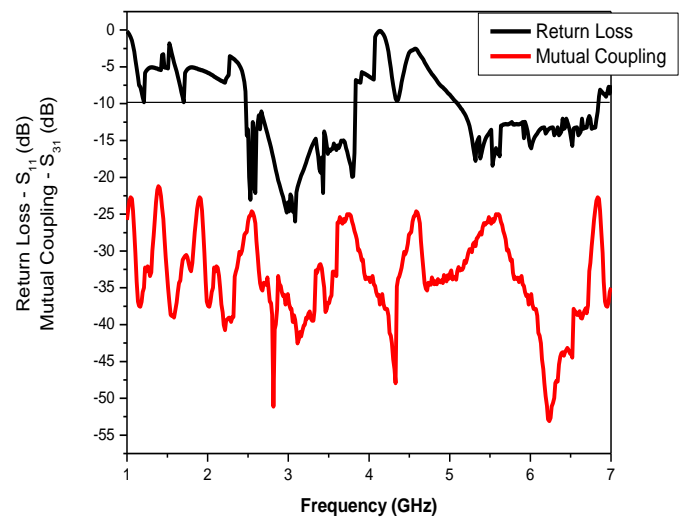

Fig.46. Plot of Return Loss and Mutual Coupling $\mathrm{S}_{31}$ versus Frequency of FEPMAA.

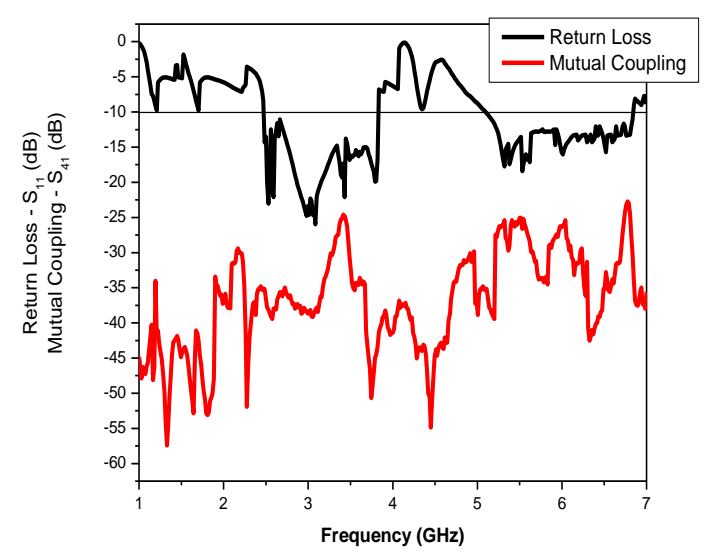

Fig.47. Plot of Return Loss and Mutual Coupling $\mathrm{S}_{34}$ versus Frequency of FEPMAA.

From Fig.45, 46 and 47, FEPMAA is resonating at dual frequencies i.e. at 3.09 and $5.53 \mathrm{GHz}$ respectively. FEPMAA is producing bandwidths of 1360 and $1740 \mathrm{MHz}$ respectively. Hence, FEPMAA is producing overall bandwidth (\%) of $75.47 \%$ as compared to FECMAA, which is producing bandwidth of $4.89 \%$. In the case of mutual coupling, FEPMAA is producing reduced mutual coupling values of $S_{21}=-26.61 \mathrm{~dB}, \mathrm{~S}_{31}=-25.77 \mathrm{~dB}$ and $\mathrm{S}_{41}$ $=-26.92 \mathrm{~dB}$ as against high values of $\mathrm{S}_{21}=-16.95 \mathrm{~dB}, \mathrm{~S}_{31}$ $=-14.22 \mathrm{~dB}$ and $\mathrm{S}_{41}=-17.30 \mathrm{~dB}$ produced by FECMAA. Here also we notice that the return loss and mutual coupling plots are no more overlapping at the resonant frequency of $5.53 \mathrm{GHz}$. There is considerable mitigation of interference level between the transmitting antenna 1 and the receiving antennas 2,3 , and 4 respectively. Thus with the loading of EBG structures in the ground plane and on the surface of FECMAA, the performance of FECMAA is improved in terms of bandwidth (\%) and mutual coupling.

Figs.48, 49, 50, 51, 52, 53 and 54 depict the graphs of return loss and mutual coupling of EEPMAA.

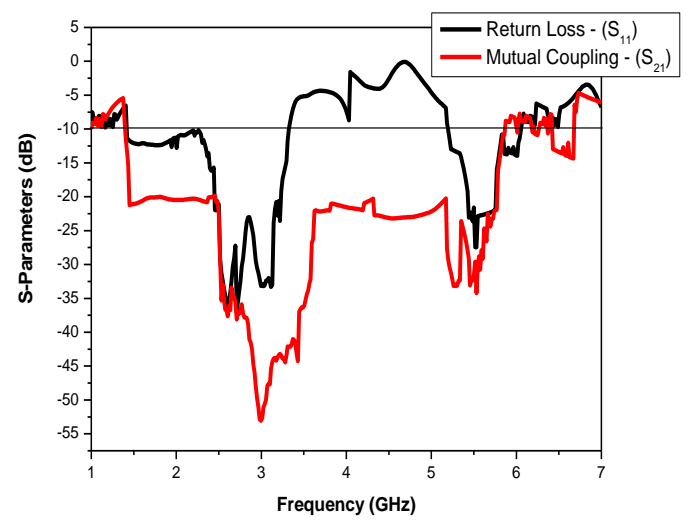

Fig.48. Graph of Return Loss and Mutual Coupling - S21versus Frequency of EEPMAA.

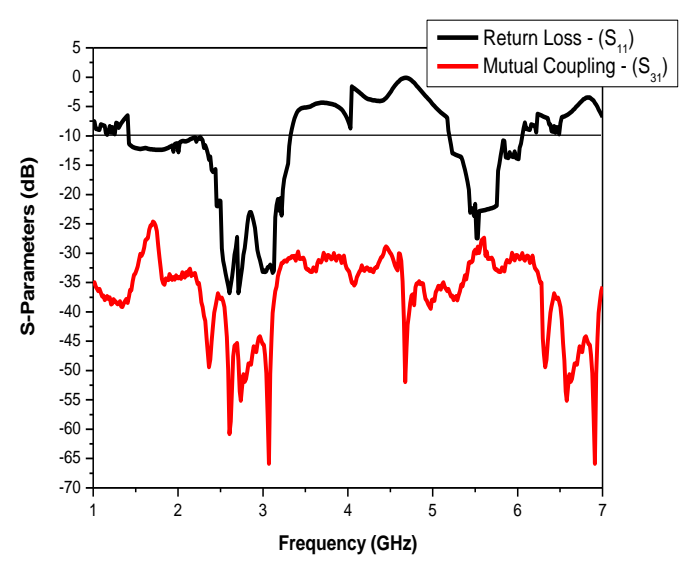

Fig.49.Graph of Return Loss and Mutual Coupling - $S_{31}$ versus Frequency of EEPMAA.

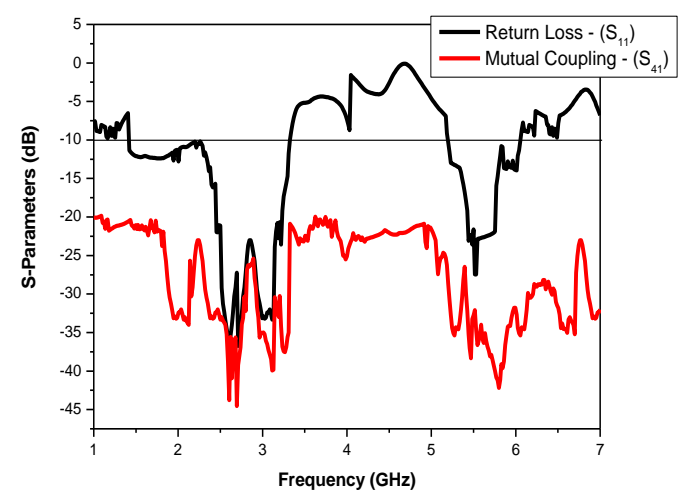

Fig.50.Graph of Return Loss and Mutual Coupling - S41versus Frequency of EEPMAA. 


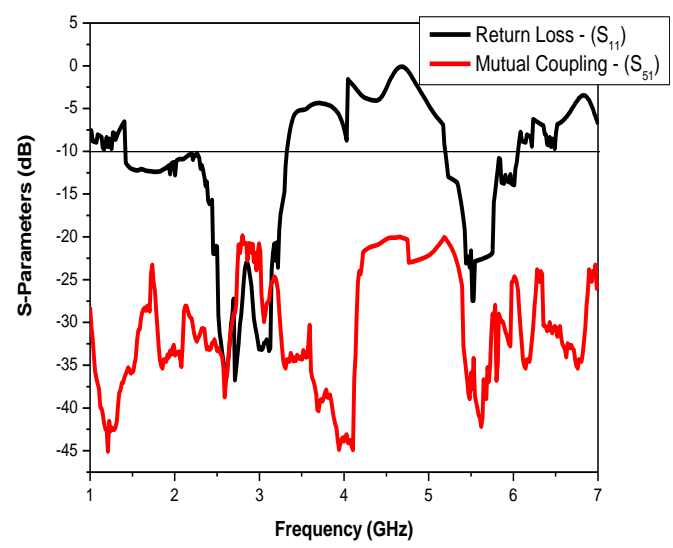

Fig.51.Graph of Return Loss and Mutual Coupling - S51versus Frequency of EEPMAA.

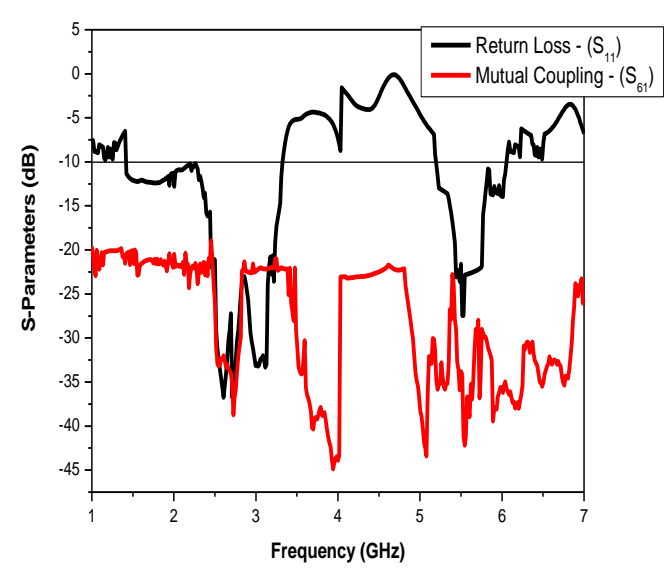

Fig.52.Graph of Return Loss and Mutual Coupling - S61versus Frequency of EEPMAA.

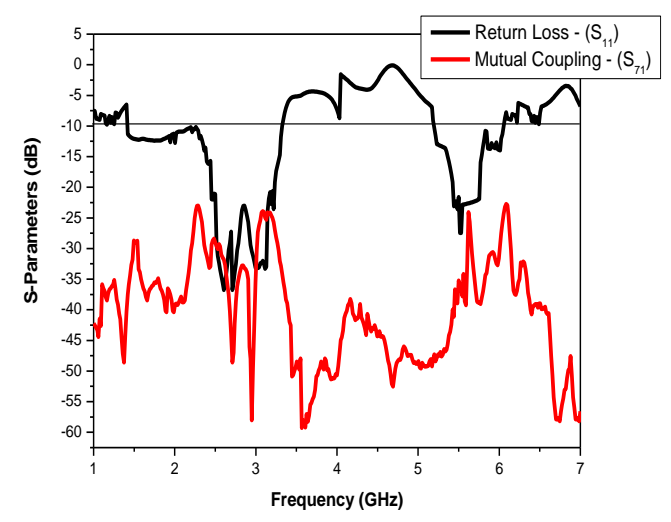

Fig.53.Graph of Return Loss and Mutual Coupling - S71versus Frequency of EEPMAA.

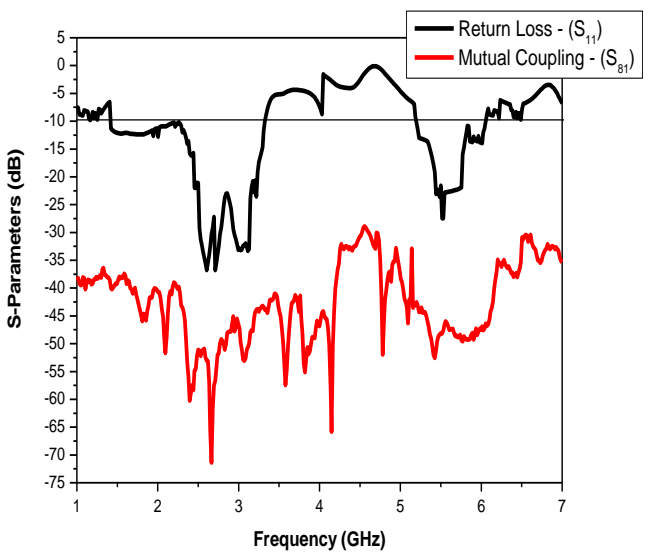

Fig.54.Graph of Return Loss and Mutual Coupling - S81versus Frequency of EEPMAA.

Figs. 48, 49, 50, 51, 52, 53 and 54 depict that EEPMAA is resonating at two frequencies i.e. 2.58 and $5.53 \mathrm{GHz}$ respectively. The return loss obtained at the fundamental resonant frequency of $2.58 \mathrm{GHz}$ is $-37.00 \mathrm{~dB}$. The bandwidths at these resonant frequencies are 1090 and 850 $\mathrm{MHz}$ respectively. Hence the overall bandwidth (\%) of EEPMAA is equal to $85.74 \%$. Thus the bandwidth (\%) of EEPMAA is much greater than that of its counterpart i.e. EECMAA equal to $4.93 \%$. After the loading of EBG structures, there is marked decrease in the mutual coupling of EECMAA. In the presence of EBG structures, the measured values of mutual coupling of EEPMAA are $\mathrm{S}_{21}=$ $-34.22 \mathrm{~dB}, \mathrm{~S}_{31}=-28.91 \mathrm{~dB}, \mathrm{~S}_{41}=-34.69 \mathrm{~dB}, \mathrm{~S}_{51}=-34.18$ $\mathrm{dB}, \mathrm{S}_{61}=-41.16 \mathrm{~dB}, \mathrm{~S}_{71}=-35.88 \mathrm{~dB}$ and $\mathrm{S}_{81}=-31.09 \mathrm{~dB}$ respectively as seen in the Figs. 48, 49, 50, 51, 52, 53 and 54. Therefore in the presence of EBG structures the performance of EECMAA is enhanced in terms of bandwidth (\%) and mutual coupling.

The bandwidth (\%) of TEPMAA, FEPMAA and EEPMAA are equal to $61.12,73.39$ and $85.74 \%$ respectively. The bandwidth (\%) produced by EEPMAA is greatest compared to TEPMAA and FEPMAA. This demonstrates that as the size of the microstrip antenna array increases from two to eight, the microstrip antenna performs better in terms of bandwidth $(\%)$.

Comparing the mutual coupling of TEPMAA, FEPMAA and EEPMAA, the reduction in mutual coupling produced by EEPMAA is highest compared to TEPMAA and FEPMAA. This implies EEPMAA produces least mutual coupling values compared to TEPMAA and FEPMAA. This confirms that as the size of the microstrip antenna array increases, the microstrip antenna performs better in terms of mutual coupling.

The parameter Gain is calculated by using the formula

$$
G=20 \log _{10}\left(\frac{4 \pi R}{x}\right)+10 \log _{10} \frac{p Y}{p t}-G t
$$


where,

$\mathrm{Pt}$ is the transmitted power.

$\operatorname{Pr}$ is the received power.

$\mathrm{R}$ is the distance between the transmitting and the receiving antennas.

$\lambda$ is the wavelength at the resonant frequency of 5.53 $\mathrm{GHz}$.

Gt is the gain of the transmitting antenna.

$\mathrm{Gt}$ is given by the formula

$$
\begin{aligned}
G t & =10 \log _{10} G s \\
G s & =\frac{2 \pi a b}{\lambda^{2}}
\end{aligned}
$$

(4)

where $\mathrm{a}$ and $\mathrm{b}$ are the length and width of the standard pyramidal horn antenna used as the transmitting antenna. The dimensions $\mathrm{a}$ and $\mathrm{b}$ are equal to 24 and $14 \mathrm{~cm}$ respectively. The distance between the transmitting antenna (standard horn antenna) and the receiving antenna is given by the formula

$$
R \geq \frac{2 D^{2}}{\lambda}
$$

where $\mathrm{D}$ is the larger dimension of the transmitting antenna equal to $24 \mathrm{~cm}$. The value of $R=71.86 \mathrm{~m}$.

In the case of TECMAA, the transmitted and received powers are equal to $8.7 \mu \mathrm{W}$ and $8.8 \mathrm{nW}$ respectively. On the other hand, the transmitted and received powers for TEPMAA are $8.7 \mu \mathrm{W}$ and $17.6 \mathrm{nW}$ respectively. Substituting all the parameter values in equation 2) the values of gain for TECMAA and TEPMAA are equal to 5.069 and $8.34 \mathrm{~dB}$ respectively. With the introduction of EBG structures, the gain of TEPMAA is enhanced to 8.34 $\mathrm{dB}$.

FECMAA is providing the transmitted and received powers equal to $8.7 \mu \mathrm{W}$ and $12.4 \mathrm{nW}$ respectively. The corresponding powers obtained in the case of FEPMAA are $8.7 \mu \mathrm{W}$ and $33.2 \mathrm{nW}$ respectively. Substituting all the parameter values in equation 2) the calculated values of gain produced by FECMAA and FEPMAA are equal to 6.81 and $11.09 \mathrm{~dB}$ respectively. Therefore, the EBG structures are aiding in an appreciable increase in the gain of FECMAA by $4.28 \mathrm{~dB}$.

As far as EECMAA is concerned, the transmitted and received powers are equal to $8.7 \mu \mathrm{W}$ and $14.35 \mathrm{nW}$ respectively. The corresponding powers for EEPMAA are $8.7 \mu \mathrm{W}$ and $61.65 \mathrm{nW}$ respectively. Substituting the relevant parameter values in equation 2) the gain values for EECMAA and EEPMAA are calculated as equal to 7.44 and $13.77 \mathrm{~dB}$ respectively. Therefore, with the loading of EBG structures in the ground plane and on surface of EECMAA, the gain of EECMAA is enhanced to $13.77 \mathrm{~dB}$.
The gain values of TEPMAA, FEPMAA and EEPMAA are compared to determine the most superior candidate. These antennas are producing gains of 8.34, 11.09 and $13.77 \mathrm{~dB}$ respectively. Among the three antennas, EEPMAA is producing the most productive gain of 13.77 $\mathrm{dB}$ compared to the other two antennas. This evidence shows that as the size of the microstrip antenna array increases in terms of number of elements, the antenna array with most number of radiating elements produces the healthiest gain compared to the lower element microstrip antenna arrays.

The parameter virtual size reduction (\%) of an antenna is determined by noting down the resonant frequencies of the antenna and its conventional antenna. The formula employed to calculate the virtual size reduction (\%) of an antenna is given by

$$
\left(\frac{f a-f b}{f a}\right) \times 100
$$

where, $f_{a}$ and $f_{b}$ are the fundamental resonant frequencies of the conventional and proposed antennas. To determine the virtual size reduction (\%) produced by TEPMAA, the fundamental resonant frequencies of TECMAA and TEPMAA are substituted in place of $f_{a}$ and $f_{b}$. For the calculation of virtual size reduction $(\%)$ of TEPMAA, $f_{a}$ and $\mathrm{f}_{\mathrm{b}}$ are equal to 5.53 and $3.36 \mathrm{GHz}$ respectively. We see that TEPMAA is resonating at a fundamental resonant frequency which is lower than that compared to TECMAA. Hence the virtual size reduction of TEPMAA is $39.32 \%$.

Similarly, to evaluate the virtual size reduction (\%) produced by FEPMAA, the fundamental resonant frequencies of FECMAA and FEPMAA are substituted in place of $f_{a}$ and $f_{b} . f_{a}$ and $f_{b}$ in this case are equal to 5.53 and $3.09 \mathrm{GHz}$ respectively. Comparing the fundamental resonant frequencies of FECMAA and FEPMAA, the fundamental resonant frequency of FEPMAA is lower than that of FECMAA. This accounts for virtual size reduction. The virtual size reduction of FEPMAA is $44.16 \%$.

The fundamental resonant frequencies of EECMAA and EEPMAA are 2.58 and $5.53 \mathrm{GHz}$ respectively. Hence to calculate the virtual size reduction $(\%)$ of EEPMAA, $\mathrm{f}_{\mathrm{a}}$ and $\mathrm{f}_{\mathrm{b}}$ are equal to 5.53 and $2.58 \mathrm{GHz}$ respectively. Therefore, the virtual size reduction of EEPMAA is equal to $53.34 \%$.

Comparing the virtual size reduction $(\%)$ or miniaturization $(\%)$ of TEPMAA, FEPMAA and EEPMAA which are equal to 39.32, 44.16 and $53.34 \%$, the one that is produced by EEPMAA is greatest and considered to be the best. This also proves that EEPMAA is the best performer compared to its counterparts TEPMAA and FEPMAA in terms of virtual size reduction (\%). This means that EEPMAA, an eight element microstrip antenna array is performing the best compared to FEPMAA, a four element microstrip antenna array and TEPMAA, a two element microstrip antenna array. This means that as the number of elements in a microstrip 
antenna array increases, the performance of the microstrip antenna array also improves in terms of miniaturization $(\%)$.

The designed and fabricated microstrip antenna arrays are compared in terms of radiation pattern. In the radiation pattern plot, forward power radiated is measured at the angle of $90^{\circ}$ and back ward power at the angle of $270^{\circ}$. Fig. 55 compares the radiation characteristics of TECMAA and TEPMAA.

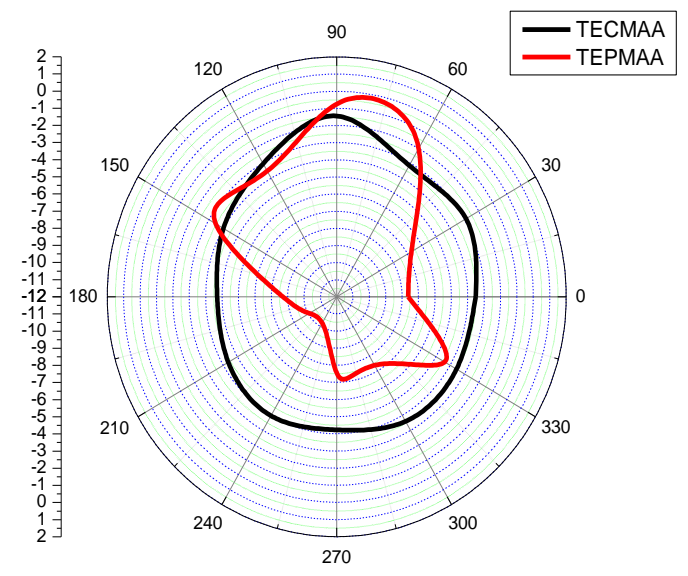

Fig.55. Radiation Patterns of TECMAA and TEPMAA.

TECMAA is producing powers in the forward and backward direction equal to -1.31 and $-4.18 \mathrm{~dB}$ respectively. On the other hand with the EBG structures present, TEPMAA is producing the corresponding powers of $-0.78 \mathrm{~dB}$ and $-7.2 \mathrm{~dB}$ respectively. Thus EBG structures are effectively decreasing the back lobe power and increasing the forward power.

The information about forward and backward powers is very useful in determining the parameter Front to Back ratio (FBR). FBR is calculated by subtracting the power radiated in the backward direction from the power radiated in the forward direction. The calculated FBR values of TECMAA and TEPMAA are 2.87 and $6.52 \mathrm{~dB}$ respectively. This means that the FBR of TEPMAA is greater than that of TECMAA. This confirms the enhanced performance of TEPMAA over its conventional antenna TECMAA.

Fig.56 depicts the radiation plots of FECMAA and FEPMAA.

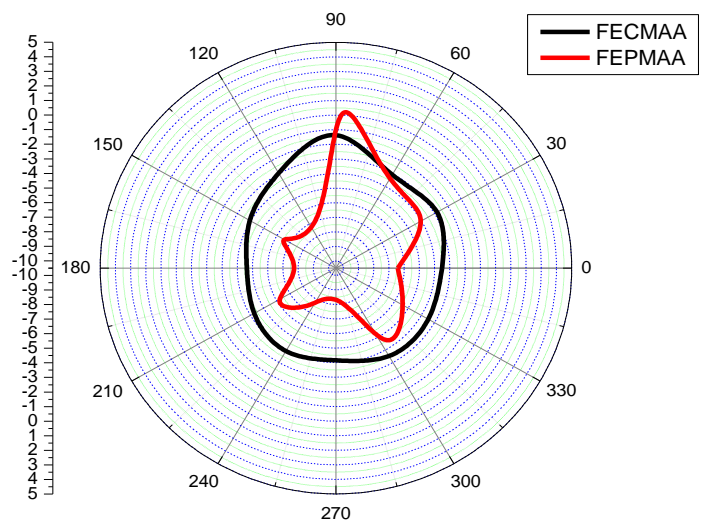

Fig.56. Radiation Patterns of FECMAA and FEPMAA.

In the absence and presence of EBG structures, the power radiated in the desired direction i.e. at the angle of $90^{\circ}$, are -2 and $-0.68 \mathrm{~dB}$ respectively. FECMAA and FEPMAA are radiating powers in the undesired direction i.e. at the angle of $270^{\circ}$ equal to -4.5 and $-8.45 \mathrm{~dB}$ respectively. The FBR values without and with EBG structures are calculated as 2.5 and $7.77 \mathrm{~dB}$ respectively. Hence EBG structures are helping FECMAA in improving the performance in terms of increase of forward power by $1.32 \mathrm{~dB}$ and reducing the back lobe radiation by $3.95 \mathrm{~dB}$ and increase of FBR by $5.27 \mathrm{~dB}$.

The radiation plots of EECMAA and EEPMAA are depicted in Fig.57.

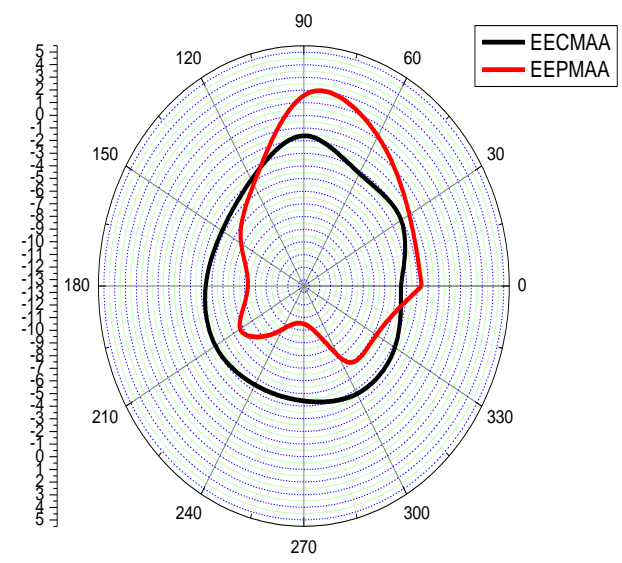

Fig.57. Radiation Patterns of EECMAA and EEPMAA.

EECMAA is radiating forward and backward powers equal to -3 and $-4.5 \mathrm{~dB}$ respectively. After integrating the EBG structures, the modified antenna array i.e. EEPMAA is radiating forward power equal to $1 \mathrm{~dB}$ and backward power of $-10.5 \mathrm{~dB}$ respectively. EEPMAA is radiating 
more power in the forward direction and less power in the backward direction compared to its competitor EECMAA.

The FBR values of EECMAA and EEPMAA are 1.5 and $11.5 \mathrm{~dB}$ respectively. The FBR of EEPMAA is much greater than EECMAA. Comparing the performances of EECMAA and EEPMAA in terms of forward power, backward power and FBR, EEPMAA is a better antenna compared to EECMAA.

The proposed microstrip antenna arrays are evaluated to determine the superiority in terms of radiation properties. In terms of power radiated in the forward direction, TEPMAA, FEPMAA and EEPMAA are radiating powers equal to $-0.78,-0.68$ and $1 \mathrm{~dB}$ respectively. As the array size is increasing the forward powers produced by the respective proposed antenna arrays is increasing. The back lobe radiation for the corresponding proposed microstrip antenna arrays are $-7.2,-8.45$ and $-10.5 \mathrm{~dB}$ respectively. As the number of elements of the proposed microstrip antenna array is increasing from 2 to 8 , the back lobe power is least for EEPMAA i.e. the proposed antenna array with eight elements and highest for TEPMAA i.e. the proposed antenna array with two elements. This makes us understand that as the microstrip antenna array size is increasing, the back lobe power is decreasing. This shows the enhanced radiation characteristics of microstrip antenna array with more elements rather than with lesser elements. The FBR values of TEPMAA, FEPMAA and EEPMAA are $6.52,7.77$ and $11.5 \mathrm{~dB}$ respectively. This confirms that among TEPMAA, FEPMAA and EEPMAA, EEPMAA has superior radiation characteristics compared to other two proposed microstrip antenna arrays.

\section{Conclusion}

The paper demonstrates the enhanced performance of two, four and eight element microstrip antenna arrays using EBG structures. The proposed microstrip antenna arrays show appreciable performance in terms of bandwidth (\%) and reduction of mutual coupling. In the presence of EBG structures higher gains are also obtained. With the help of EBG structures the proposed microstrip antenna arrays are possessing good radiation characteristics in forward and backward directions. Moreover, the proposed eight element microstrip antenna array is showing the best performance compared to two and four element proposed microstrip antenna arrays which demonstrates the fundamental aspect of antenna arrays

\section{References}

[1] Constantine A. Balanis, Antenna Theory, Analysis and Design, John Wiley \& Sons Inc $2^{\text {nd }}$ edition 1997.

[2] I.J.Bahl and P.Bhartia, Microstrip Antennas, Artech House, 1980.

[3] Reinhold Ludwig and Pavel Bretchko, RF Circuit Design: Theory and Applications, 2009.
[4] Fan Yang and Yahya Rahmat-Samii, Electromagnetic Band Gap Structures in Antenna Engineering, 2009.

[5] D. N. Elsheakh, E. A. Abdallah, M. F. Iskander and H. A. Elsadek, "Microstrip Antenna Array with New 2DElectromagnetic Band Gap Structure Shapes to Reduce Harmonics and Mutual Coupling," Progress in Electromagnetic Research C,Vol.12, pp.203213,2010 .

[6] Hossein Sarbandi Farahani, Mehdi Veysi, Manouchehr Kamyab and Alireza Tadjalli, "Mutual Couplin Reduction in Patch Antenna Arrays Using a UC-EBG Superstrate," IEEE Antennas and Wireless Propagation Letters, Vol. 09, pp. 57-59, 2010.

[7] Zeev Iluz, Reuven Shavit and Reuven Bauer, "Microstrip Antenna Phased Array with Electromagnetic Bandgap Substrate," IEEE Transactions on Antennas and Propagation, Vol.52, Issue. 06, pp. 1446- 1453, Jun 2004.

[8] S.Yamini and B.Panjavarnam, "Microstrip Patch Antenna Integrated with EBG," IEEE Xplore.

[9] Hassan Sajjad, Sana Khan and Ercument Arvas, "Mutual Couplin Reduction in Array Elements Using EBG Structures," IEEE Xplore.

[10] R. Gupta and M. Kumar, "Bandwidth Enhancement of Microstrip Patch Antennas by Implementing Electromagnetic Bandgap (EBG) Structures," Proc. of Fourth International Conference on Computational Intelligence and Communication Networks (CICN), pp. 15-18, 2012.

[11] Halim Boutayeb and Tayeb A. Denidni, "Gain Enhancement of a Microstrip Patch Antenna Using a Cylindrical Electromagnetic Crystal Substrate," IEEE Transactions on Antennas and Propagation, Institute of Electrical and Electronics Engineers, Vol.55, Issue. 11, pp. 3087- 3092, 2007.

[12] Shiji Shajahan and A. Vasuki, "A Broadbanding Microstrip Patch Antenna Using Electromagnetic Band Gp Structures," International Journal of Pure and Applied Mathematics, Vol.116, Issue. 11, pp. 71- 80, 2017.

[13] K. Rama Devi, A. Mallikarjuna Prasad and A. Jhansi Rani, "Design of a Pentagon Microstrip for Radar Altimeter Application," International Journal of Web and Semantic Technology, Vol.03, Issue. 04, pp. 3142, Oct 2012.

[14] Sanjiwani S.Patil and V.V.Joshi, "Performance Improvement of Microstrip Antenna Using EBG Structure," International Journal of Emerging Technology and Advanced Engineering, Vol.05, Issue. 07, pp. 74-78, Jul 2015.

[15] F. Benykhlef and N. Boukli-Hacene, "EBG Structures for Reduction of Mutual Coupling in Patch Antenna Arrays," Journal of Communications Software and Systems, Vol.13, Issue. 01, pp. 09- 14, Mar 2017.

[16] Sarveshwanker and Divyanshu Rao, "Fractalized Meander Line EBG Based Microstrip Patch Slot Antenna," International Journal of Advanced Research in Electronics and Communication Engineering, Vol.04, Issue.10, pp. 2633-2642, Oct 2015.

[17] Shahrokh Jam and Hossein Malekpoor, "Compact $1 \times 4$ Patch Antenna Array By Means of EBG Structures With Enhanced Bandwidth," Microwave and Optical Technology Letters, Vol.58, Issue. 12, pp. 2983- 2989, Dec 2016. 